\title{
Galveston Orientation Amnesia Test (GOAT)
}

\author{
GALVESTON ORIENTATION AMNESIA TEST (GOAT) \\ GALVESTON ORIENTATION AMNESIA TEST (GOAT)
}

\author{
Silvia Cristina Fürbringer e Silva ${ }^{1}$, Regina Márcia Cardoso de Sousa ${ }^{2}$
}

\begin{abstract}
Closed head injury (CHI) is frequently followed by post-traumatic amnesia (PTA) and is characterized by a transitory state of confusion and disorientation. The PTA duration has been used to quantify the $\mathrm{CHI}$ severity and to predict disorders in cognitive functions, as well as to foresee any alteration in the functional capacity of posttrauma victims. The Galveston Orientation Amnesia Test (GOAT) is the first systematized instrument created, and the most broadly applied, to assess PTA. This article presents the GOAT, the conceptual basis for the development of the instrument, and its adaptation and validation to the Brazilian culture. In addition, the article describes the application of the instrument and makes comments on the restrictions of its use. Brazilian research results showed evidences of the GOAT's validity. They also point to the indicators of post-trauma conditions in which the GOAT must be applied, and highlight the difficulties in the application of the instrument.
\end{abstract}

\section{KEY WORDS}

Amnesia.

Trauma Severity Indices.

Head injuries, closed.

Validation studies.

\section{RESUMO}

O trauma crânio-encefálico contuso (TCEC) é freqüentemente seguido pela amnésia pós-traumática (APT), caracterizada como um estado transitório de confusão e desorientação. Sua duração tem sido utilizada para quantificar a gravidade do TCEC e prever distúrbios nas funções cognitivas, assim como para antever as alterações na capacidade funcional das vítimas pós-trauma. $O$ Galveston Orientation Amnesia Test (GOAT) é o primeiro instrumento sistematizado criado e o mais amplamente utilizado para avaliar a APT. Este artigo apresenta esse instrumento, as bases conceituais para seu desenvolvimento e a adaptação e validação do GOAT para cultura brasileira. Além disso, descreve sua aplicação e comenta as restrições do seu uso. Resultados de pesquisas realizadas em nosso meio contribuíram para as evidências sobre a validade do GOAT. Também apontaram os indicadores do momento pós-trauma em que o GOAT deve ser aplicado e destacaram as dificuldades no uso desse instrumento.

\section{DESCRITORES}

Amnesia.

Índices de Gravidade do Trauma.

Traumatismos cranianos fechados.

Estudos de validação.

\section{RESUMEN}

El trauma cráneo-encefálico contuso (TCEC) es frecuentemente seguido por la amnesia pos-traumática (APT), caracterizada como un estado transitorio de confusión y desorientación. Su duración ha sido utilizada para cuantificar la severidad del TCEC y prever alteraciones en las funciones cognitivas, tanto como para antever las dificultades en la capacidad funcional de las víctimas pos-trauma. El Galveston Orientation Amnésia Test (GOAT) es la primera encuesta sistematizada que fue creada y el mas am-pliamente utilizada para evaluar la APT. Esta publicación presenta esta encuesta, las bases conceptuales para su desarrollo y la adaptación y validación del GOAT para la cultura brasileña. Además, describe su aplicación y limitaciones en el uso. Resultados de pesquisas brasileñas contribuyeron para las evidencias sobre la validad del GOAT. También apuntaron los indicadores del momento pos-trauma en que el GOAT debe ser aplicado y destacaron las dificultades en el uso de esa encuesta.

\section{DESCRIPTORES}

Amnesia.

Índices de Gravedad del Trauma. Traumatismos cerrados de la cabeza. Estudios de validación.

${ }^{1} \mathrm{PhD}$ by the University of São Paulo College of Nursing. Professor of the Nursing and Medicine Undergraduate Courses and of the Nursing Graduate Program at Centro Universitário São Camilo. São Paulo, SP, Brazil. ssilva@scamilo.edu.br ${ }^{2}$ Free-Lecturer of the Medical-Surgical Nursing Department at University of São Paulo College of Nursing. São Paulo, SP, Brazil. vian@usp.br

\begin{tabular}{|c|c|c|}
\hline (0) & $\begin{array}{l}\text { Received: 30/01/2009 } \\
\text { Approved: 16/04/2009 }\end{array}$ & $\begin{array}{r}\text { Rev Esc Enferm USP } \\
2009 ; 43(\text { Spe):1027-33 } \\
\text { www.ee.usp.br/reeusp/ }\end{array}$ \\
\hline
\end{tabular}




\section{INTRODUCTION}

The Galveston Orientation Amnesia Test (GOAT) is an instrument originally created by Levin, O'Donnel and Grossman and first published in $1979^{(1)}$. It was born in the American culture, and was adapted and validated to our cultural environment in $2002^{(2)}$. It is composed of ten questions that assess post-traumatic amnesia (PTA) in victims of closed head injury $(\mathrm{CHI})$ following the injury.

$\mathrm{CHI}$ is often followed by PTA, and is defined as a transitory state of confusion and disorientation characterized by anterograde and retrograde amnesia, and behavior disorders, among them insomnia, psychomotor agitation, fatigue, confabulation, and occasionally serious affective and psychotic symptoms ${ }^{(3-5)}$. The resolution of PTA is heralded by the return of orientation and continuous memory.

Anterograde amnesia is the major characteristic of PTA and is sometimes used as its synonym. However, a distinction between these two clinical conditions is necessary, since the first refers to one's incapacity to form new memories after a determined event and is a specific memory deficiency. On the other hand, PTA refers to a sub-acute state following $\mathrm{CHI}$ that can include the previously described behavioral alterations as well as alterations in the retrograde memory ${ }^{(6)}$. In addition, the anterograde memory deficiency observed during PTA is specifically identified in the declarative memory that refers to the record of facts, events or knowledge, while the procedural memory (memory of motor or sensorial capacities or abilities) is spared ${ }^{(7)}$.

The duration of PTA after $\mathrm{CHI}$ is frequently used to quantify the severity of this type of trauma and to predict the functional capacity of victims. Thus, there are several authors that propose this parameter to differentiate victims according to distinct levels of $\mathrm{CHI}$ severity, and to assess its consequences. The longer the PTA duration, the worse the expected functional result $t^{(4,8-11)}$.

The duration of this syndrome is also applied in developed countries as an indicator of rehabilitation feasibility for patients who present with $\mathrm{CH}{ }^{(5,11-13)}$. From the studied behavioral sequelae, PTA has repeatedly revealed itself as the best isolated indicator to predict either cognitive function problems or impairments in the victims' daily activities. In many cases, PTA is a better indicator than the duration and depth of the coma ${ }^{(8)}$.

Therefore, it is clinically very relevant to acknowledge PTA and its implications after a $\mathrm{CHI}$, since it allows for additional information for both the family and the victim; also, it provides support in the planning and assessment of rehabilitation programs, offering indications of PTA's physiopathology.
Up until the 1980's, the duration and the termination of PTAs were retrospectively established by questioning patients about their memory, after restoration of the continuous memory ${ }^{(1)}$.

Some criticisms related to the retrospective measure of memory were presented by several authors, who questioned the accuracy of achieved data. They affirmed that whenever the PTA duration was retrospectively determined, the identification of pathology was dependent on the judgment of the patient himself and on his family members' memories, which are often associated with moments of intense stress that can lead to false memories. The result of the assessment can also be inadequate due to the presence of memory islands during the PTA period that confound the identification of its termination ${ }^{(1)}$.

The GOAT was one of the first in a series of instruments whose purpose was to prospectively establish the PTA duration following $\mathrm{CHI}$. Although the instrument questions the patient on events that took place after and prior to the injury, and therefore achieves information that allows for retrospective estimation of the amnesia length of time, its creators proposed a prospective assessment, that is to say, repeated evaluations of the patient after $\mathrm{CHI}$, until the test score indicates a termination of the amnesia period ${ }^{(1)}$.

\section{THE INSTRUMENT'S CONCEPTUAL BASIS}

In 1946, Russel and Nathan ${ }^{(14)}$ were already studying the pathological basis of PTA. They affirmed that whenever an individual suffered a traumatic cerebral injury there was a paralysis of the cerebral function (motor, sensorial, reflexive, and rational); from then on, further occurrences were not recorded anymore, resulting in a permanent amnesia for events that took place during this period.

The most traditional definition of PTA, and the most applied criteria for its assessment, are based on the presupposition that the post-traumatic state involves confusion and amnesia, and that when one regains normalcy of both functions it means that the amnesia has ended $^{(15)}$. Based on this presupposition, the natural history of recovery from a diffuse or chronic encephalic pathology generally assumes a similar pattern. Although patients with focal primary injuries present some or all of the components of such a pattern, the course of recovery is not as predictable as in diffuse primary injuries ${ }^{(16)}$.

This natural history can be described as having three major phases: the first phase is the period characterized by the lack of voluntary verbal and motor responses, as well as the absence of spontaneous eye opening; in the second phase, the patient is confused and amnesic for daily events, 


\begin{abstract}
and can evidence behavioral disorders; the third and last phase displays a gradual restoration of the cognitive function and daily activities ${ }^{(12,16)}$. In this description, PTA is the initial recovery stage following an interval of low awareness, and includes confusion and anterograde amnesia.
\end{abstract}

More recently, some research suggests that although confusion and amnesia occur at the same time during PTA recovery, they can follow different recovery processes, and the resolution for each one of them can take place at different periods of time ${ }^{(15)}$.

\section{DEVELOPING THE ORIGINAL INSTRUMENT}

The GOAT was developed to assess the broadest sense of orientation: time, place, and person. Its questions range from prior to post-CHI, the period in which PTA can occur ${ }^{(1)}$.

The GOAT's core action is to briefly assess temporal orientations by requesting the patient to recite day of the week, day of the month, year, and time of the day (questions 6 to 10 of the GOAT). These questions derive from the assessment of temporal orientation proposed by Benton, Van Allen and Fogel in $1964^{(17)}$.

Since its publication, the GOAT has not undergone any alteration or revision, although it is the target of criticism for presenting several orientation items in comparison to the few items that evaluate anterograde memory (the major characteristic of PTA). Even if the patient has amnesia, as a consequence of the responses to orientation-related items, it is still possible to achieve a higher score than the one that indicates the termination of PTA ${ }^{(11)}$.

In the publication that introduces the GOAT, the authors $^{(1)}$ described three validation analyses for the instrument, bearing in mind the PTA duration in days, determined by the application of the GOAT. One of the analyses compared this duration against the results of the items in the Glasgow Coma Scale (GCS1), determined by the neurosurgeon at the time of the patient's admittance process. Another analysis applied the injuries diagnosed by means of computerized tomography (CT scan) as a parameter, and the last analysis observed the relationship between the PTA duration determined by the GOAT and the long-term functional capacity of the victims.

Results showed that the GOAT scores were strongly related with the Eye Opening and Verbal and Motor Response measurements of the GCS1; at the same time, the application of the scale was quite relevant in assessing the relationship between the PTA duration established by the test and $\mathrm{CHI}$ long-term results ${ }^{(1)}$.

In addition , in the GOAT's performance analysis against computerized tomography, the bilateral, diffuse injury was more strongly associated with an amnesia intervals $>14$ days when compared with a restricted injury to one cerebral hemisphere ${ }^{(1)}$.

\section{DESCRIBING THE FORMAT OF THE ORIGINAL INSTRUMENT}

The GOAT is an instrument composed of 10 questions that assesses orientation and amnesia. Besides the patient's temporal orientation (questions 6 to 10), the GOAT presents questions regarding the patient's name, address, and birth date (question 1), as many patients undergoing recovery from $\mathrm{CHI}$ are confused concerning basic information. Memory distortions can involve geographic orientation disorders; as such, the GOAT also proposes questions related to this aspect. The patient must also identify his location and inform that he was admitted into a hospital (question 2). Question 3 refers to the hospital admittance date; questions 4 and 5 test the patient on events that took place after and before the injury, respectively. All this information must be confirmed by the data recorded in the patient's bedside assessment, or through the patient's family members. The professional then, determines the score that must be assigned to the patient based on this set of information ${ }^{(1)}$.

\section{APPLYING THE GOAT}

The 10 questions of the GOAT are orally administered to patients, and each question has a determined number of error scores that must be assigned when any response goes astray from the correct one. This score is displayed in parentheses after each question of the instrument ${ }^{(1)}$.

The correction of wrong responses provided by the patient is a relevant procedure; he must also be notified that the test will be reapplied on the following day in order to assess his memorization capacity.

The GOAT's total score must be achieved by subtracting from 100 the total amount of error scores (Total score = 100 - total amount of error scores). Scores lower than 75 point to the fact that the victim is still experiencing amnesia. When the victim reaches a score lower than or equal to 75 on two consecutive days, it means that PTA is resolved . Therefore, the GOAT must be applied when the patient is capable of cooperating, and it should be repeated on a daily basis, until a score of 75 is consistently reached; that is, until the score is kept equal to or higher than 75 for a minimum of two consecutive days ${ }^{(1,12)}$.

In assessing $\mathrm{CHI}$ by the PTA duration, a period of amnesia time of less than one hour indicates a light trau$\mathrm{ma}$, and the trauma is moderate for a time that ranges between one and 24 hours. Victims whose PTA extends for over a day are considered as having a severe encephalic injury ${ }^{(9)}$.

As per the application of the GOAT, it is worth emphasizing some observed difficulties concerning the restrictive conditions identified in clinical practice, most of all those related to the incapacity of the victims to engage in verbal communication. 
The review of the international literature points to individuals consistently out of coma ${ }^{(12)}$ as a prerequisite for the application of the scale; such a description is still vague for the application of the instrument.

It was then necessary to find indicators of the post-trauma assessment for the employment of the GOAT questions. As the GCS1 is considered to be a widely used and recognized scale worldwide for the assessment of post-CHI victims, it can be a relevant indicator of the appropriate moment for the application of the GOAT.

The gaps observed in the timing of the test's application led to the implementation of a study ${ }^{(2,18)}$ aimed at identifying the most adequate period of time for the application of the GOAT by the use of total and partial GCS1 scores. Another follow-up study for $\mathrm{CHI}$ victims admitted to a reference center for traumas in the city of Sao Paulo analyzed the results of the application of the instruments. As per the test's applicability, patients with $\mathrm{GCS} 1 \geq 12$ received the test; however, the PTA termination was observed in patients with score $\geq 14$ using this scale $e^{(2,18)}$.

Victims with GCS1 scores of 14 and 15, a partial score of 3 or 4 in the Eye Opening item, 4 or 5 in the Verbal Response item, and 6 in the Motor Response item achieved a score 75 in the GOAT. These results point to the application of this test after the victims reached the GCS1 scores ${ }^{(2,18)}$.

\section{ADAPTATION AND VALIDATION FOR THE BRAZILIAN CULTURE}

The GOAT, originally developed in the English language, was given the authors' permission to be translated into Portuguese. This process took place in three stages: the translation into Portuguese; the back-translation into English; and the assessment of the equivalence between the original instrument and the back-translated version.

Two nurses specializing in Intensive Therapy, with a full grasp of both idioms (Portuguese and English), were involved in the Portuguese version. The back-translation was performed by two Brazilians who were fluent in the English language. One Canadian specialist in Neuroscience performed the assessment of equivalence between the original instrument and the back-translated version.

In the translation and back-translation phases, the specialists worked independently and later combined both translations into a single entity .

The translation process followed a smooth course and the comparison between the original and back-translated scales resulted in the indication, by the assessor, of the idiomatic and conceptual equivalence of both versions of the instrument ${ }^{(2,19)}$.
It is worth highlighting, however, that when comparing the original and the back-translated scales, the assessor made the following comment regarding the second part of question 5 :

The back-translation is accurate, but the original version is confusing when it says the first event you recall before the injury. The phrase in the previous question which refers to 'last thing you remember before...' makes more sense.

Bearing this comment in mind, we chose the translation the last thing you remember before the accident for the second part of question 5 , according to what can be presented in the translated document.

Following its translation into Portuguese, the GOAT was named Teste de Amnésia e Orientação de Galveston. After undergoing the converging and diverging validation process, the instrument was then assessed according to its reliability and validity. The procedure encompassed the application of the instrument on patients admitted to a government hospital, a reference center for the assistance of victims with traumas. Throughout the data collection process, 73 patients were located and followed up in different health-care units for daily assessment. $\mathrm{CHI}$ victims from 12 to 60 years of age, with neither a previous diagnosis of cranio-encephalic trauma nor memory alteration, assisted in the study locus after sustaining a trauma, and who were ad-mitted for treatment in the period that ranged from January 3rd to May 3rd 2001, took part in the case study ${ }^{(2,19)}$.

The instrument's reliability was assessed by the internal consistency analysis of the items by means of the Cronbach's alpha coefficient, and the reference value adopted as acceptable (good reliability) was equal to or higher than 0.7 . One of the conditions for the alpha calculation is that all involved items are positively correlated, and this hypothesis was satisfied by all questions that compose the instrument. The calculated alpha for the instrument reached 0.76 , therefore higher than the one adopted as acceptable ${ }^{(2,19)}$.

Keeping in mind that both the alteration of the victim's initial awareness level and the PTA duration have been considered as important indicators of the $\mathrm{CHI}$ severity profile, and that the GCS1 and the GOAT are instruments indicated to detect such alterations, some hypotheses were formulated in order to validate the GOAT.

As per the converging validity, one of the formulated hypotheses affirms that the value achieved in the first GCS1 assessment by means of the neurosurgery exam is positively correlated with the obtained scores of the GOAT's initial assessment. The positive correlation presupposition is based on the significance of the instrument's scores, which in both applications presented a similar pattern : noticeable 
alterations are assigned low scores and states of normality in the measured parameter are indicated by higher values.

Another aspect of the converging validity was a further hypothesis that presupposes that the length of days of PTA established by the GOAT presents a negative correlation with the scores of the first GCS1 assessment of the neurosurgery team or physician. In this case, the correlation hypothesis is negative due to the presupposition that the longer the PTA period, the more severe the $\mathrm{CHI}$; on the other hand, higher GCS1 scores indicate lower severity of the injury.

In both hypotheses previously described, there is an expected correlation between variables; therefore, a converging validity profile for the instrument must be taken into account. The Spearman's Rank correlation coefficient was applied to test the converging validity hypothesis.

The study showed a statistically significant positive ordinal correlation $\left(r_{s}=0.56 ; p<0.05\right)$ between the GCS1 score and the scores of the GOAT's first assessment. Hence, the GCS1 high scores - indicating light trauma - tended to be associated with high scores in the GOAT during the first assessment for the follow-up process of the victims. On the other hand, the GCS1 low score - indicating severe $\mathrm{CHI}$ was related with the GOAT's low scores ${ }^{(2,19)}$.

The study also showed a statistically significant negative correlation ( $p<0.05$ ) between the GCS1 and the PTA duration. In this case, the identification of light $\mathrm{CHI}$ through the GCS1, indicated by a high score, was related to short periods of amnesia. Similarly, the indication of a severe $\mathrm{CH}$ was associated with longer periods of PTA. Such results are evidence of the GOAT's converging validity, as the resulting values of this instrument's application are correlated with another measurement method for the same concept, that is, the $\mathrm{CHI}$ severity measured by the $\mathrm{GCS} 1^{(20)}$.

In the beginning, the discriminatory capacity of the GOAT was assessed by comparing the average scores achieved in the first application on victims from one case group and one control group. The control group was composed of patients who had moderate and light trauma pointed out by the GCS1 scores (9-15), and the case group was composed of victims with severe trauma, according to the scores of the same scale $(3-8)^{(2,19)}$.

This analysis considered that in the first assessment performed by the GOAT, light and moderate $\mathrm{CHI}$ victims should be considered as being within the last phase of the PTA period and, therefore, should achieve scores close to normal. However, the same concept should not be applied to those who were indicated as having severe trauma ${ }^{(2,19)}$.

Following the instrument's test of discriminatory validity, the procedure considered the PTA duration in days, determined by the daily application of the GOAT, until the indication of termination of the amnesia, and the same groups were formed according to the $\mathrm{CHI}$ indicated by the GCS1 ${ }^{(2,19)}$.
The instrument's discriminatory validity was assessed by comparing the averages of the case group and the control group. The normal scores achieved by the first GOAT's assessment and the PTA duration in days observed by the Kolmogorov-Smirnov test allowed for comparison using the Student's t-Test for independent samples ${ }^{(2,19)}$.

The control group, characterized by light and moderate $\mathrm{CHI}$, showed a GOAT average score highly superior to that of the case group, who had more severe $\mathrm{CHI}$. There was a statistically significant incidence $(p<0.05)$ of the control group presenting an average score higher than the case group's; such a result indicates that the instrument displays a discriminatory validity, since it distinguishes the groups of respondents that would theoretically bring about differences in the assessed attribute ${ }^{(20)}$.

When the PTA duration variable was analyzed, the comparison revealed that there is statistical evidence that the average number of days of amnesia in the case group exceeds the control group's. This result reaffirms the proof of the GOAT's discriminatory capacity ${ }^{(2,19)}$.

In all of the validation analyses, the $\mathrm{p}$ value was calculated in association with the hypothesis of nullity $\left(\mathrm{H}_{0}\right)$ adopted in each test, and the result was considered as statistically significant in the analyses in which the $p$ value was lower than $0.05^{(2,19)}$.

\section{FINAL CONSIDERATIONS}

Since its publication, the GOAT has been widely applied. Studies that applied this test have shown that it is an important instrument to detect PTA and to determine its duration ${ }^{(4,10)}$.

Notwithstanding, the use of the GOAT's scoring to determine the resolution of PTA identifies a stage of recovery that seems to be more related to the return of the orientation capacity than with the recovery of spontaneous memory. According to some authors, patients with more severe traumas display an amnesia profile that contributes to the GOAT score, but in lighter traumas, attention and confusion are the primary factors that contribute to the scoring ${ }^{(21)}$.

The use of the GOAT as an instrument to establish the termination of amnesia limits the researcher's capacity to distinguish from a status of confusion to alteration of posttraumatic memory. In the GOAT's framework, the predominance of orientation measures is clear, and matches the presupposition that the period of amnesia is the initial phase of recovery following an interval of low level of awareness.

In addition, the experience of determining the length of time of PTA has prospectively evidenced difficulties and restrictions to be appraised: for example, the daily application of the instrument can be extended for many days; the period of admittance in the hospital is quite 
feasible for the daily assessment processes, but the length of time of PTA often exceeds this period; there are several conditions throughout the hospital admittance period of

\section{REFERENCES}

1. Levin HS, O'Donnell VM, Grossman RG. The Galveston Orientation and Amnesia Test: a practical scale to assess cognition after head injury. J Nerv Ment Dis. 1979;167(11): 675-84.

2. Silva SCF. Galveston orientation and amnesia test: validação, aplicabilidade e relação com a Escala de Coma de Glasgow [dissertação]. São Paulo: Escola de Enfermagem, Universidade de São Paulo; 2002.

3. Baird A, Papadopoulou K, Greenwood R, Cipolotti L. Memory functions after resolution of post-traumatic amnesia. Brain Inj. 2005;19(10):811-7.

4. De Guise E, Leblanc J, Feys M, Thomas H, Gosselin N. Effect of an integrated reality orientation programme in acute care on post-traumatic amnesia in patients with traumatic brain injury. Brain Inj. 2005;19(4):263-9.

5. Nakase-Thompson R, Sherer M, Yablon SA, Nick TG, Trzepacz PT. Acute confusion following traumatic brain injury. Brain Inj. 2004;18(2):131-42.

6. Weir N, Doig EJ, Fleming JM, Wiemers A, Zemljic C. Objective and behavioral assessment of the emergence from posttraumatic amnesia (PTA). Brain Inj. 2006;20(9):927-35.

7. Ahmed S, Bierley R, Sheikh JI, Date ES. Post-traumatic amnesia after closed head injury: a review of the literature and some suggestions for further research. Brain Inj. 2000;14(9):765-80.

8. Greenwood R. Value of recording duration of post-traumatic amnesia [commentary]. Lancet. 1997;349(9058):1041-2.

9. Muñhoz-Céspedes JM, Paúl-Lapedriza N, Pelegrín-Valero C, Tirapu-Ustarroz J. Factores de pronóstico en los traumatismos craneoencefálicos. Rev Neurol. 2001;32(4):351-64.

10. Pastorek NJ, Hannay HJ, Contant CS. Prediction of global outcome with acute neuropsychological testing following closed head injury. J Int Neuropsychol Soc. 2004;10(6): 807-17.

11. Tate RL, Pfaff A, Jurjevic L. Resolution of disorientation and amnesia during post-traumatic amnesia. J Neurol Neurosurg Psychiatry. 2000;68(2):178-85.
$\mathrm{CHI}$ victims that make verbal communication impossible and hinder the memory assessment, regardless of the method $^{(2,22)}$.

12. Ellenberg JH, Levin HS, Saydjari C. Posttraumatic amnesia as a predictor of outcome after severe closed head injury. Arch Neurol. 1996;53(8):782-91.

13. Nakase-Richardson R, Yablon SA, Sherer M. Prospective comparison of acute confusion severity with duration of posttraumatic amnesia in predicting employment outcome after traumatic brain injury. J Neurol Neurosurg Psychiatry. 2007; 78(8):872-6

14. Russell WR, Nathan PW. Traumatic amnesia. Brain. 1946; 69(3):280-300.

15. McFarland K, Jackson L, Geffen G. Post-traumatic amnesia: consistency-of-recovery and duration-to-recovery following traumatic brain impairment. Clin Neuropsychol. 2001; 15(1): 59-68.

16. Povlishock JT, Katz DI. Update of neuropathology and neurological recovery after traumatic brain injury. J Head Trauma Rehabil. 2005;20(1):76-94.

17. Benton AL, Van Allen MW, Fogel ML. Temporal orientation in cerebral disease. J Nerv Ment Dis. 1964;139:110-9.

18. Silva SCF, Sousa RMC. Galveston orientation and amnesia test: applicability and relation with the Glasgow Coma Scale. Rev Lat Am Enferm. 2007;15(4):651-7.

19. Silva SCF, Sousa RMC. Galveston orientation and amnesia test: translation and validation. Acta Paul Enferm. 2007; 20 (1):24-9.

20. McDowell I, Newell C. The theoretical and technical foundations of health measurement. In: McDowell I, Newell C. Measuring heath: a guide to rating scales and questionnaires. Oxford: Oxford University Press; 1996. p. 10-46.

21. Stuss DT, Binns MA, Carruth FG, Levine B, Brandys CE, Moulton, et al. The acute period of recovery from traumatic brain injury: posttraumatic amnesia or post-traumatic confusional state? J Neurosurg. 1999;90 (4):635-43.

22. Silva SCF, Sousa RMC. Avaliação da amnésia pós-traumática em vítimas de trauma crânio-encefálico. Rev Paul Enferm. 2006;25(2):66-73. 


\section{APPENDIX}

Instrumento Adaptado: Teste de Amnésia e Orientação de Galveston*

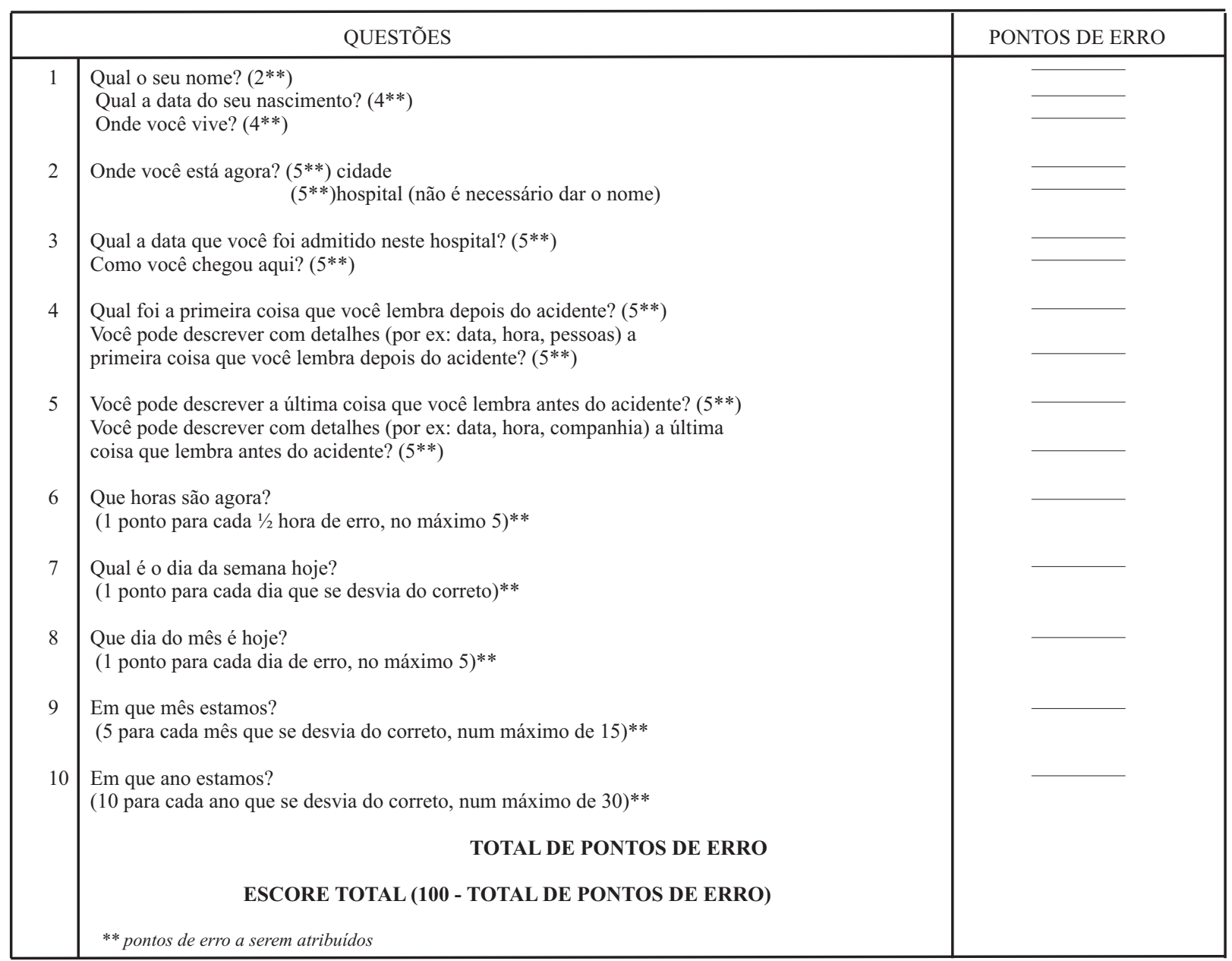

*Instrumento adaptado por: Silva SCF, Sousa RMC (2002).

*Instrumento original elaborado por Levin HS, O'Donnell VM, Grossman RG (1979). 